\title{
Knowledge Attitude and Practice Toward Chikungunya Infection Among Kassala Community in Sudan 2018-2019
}

\author{
Manal Bilal Mohamed Hassan ${ }^{1}$, Mohamed Ibrahim Osman Ahmed ${ }^{2}$, \\ Sultan Dhaif Allah Awad Alharbi ${ }^{2}$, Uthman Abdull Ah Mohammed Albeshi ${ }^{2}$, \\ Ebtisam Hanshool Mauof Al-Gathmi ${ }^{3}$ \\ ${ }^{1}$ General Administration and Training Education and Development, Omdurman Islamic University, Omdurman, Sudan \\ ${ }^{2}$ Erada Complex for Mental Health Riyadh, Riyadh, Saudi Arabia \\ ${ }^{3}$ Tiaf Health, Tiaf, Saudi Arabia
}

\section{Email address:}

Manalbela152@Gmail.com (M. B. M. Hassan), wadow75@gmail.com (M. I. O. Ahmed), Sult111an@hotmail.com (S. D. A. Awad Alharbi), Albeshi.uth1331@hotmail.com (U.A.Ah M. Albeshi), eal-gethami@moh.gov.sa (E.H. M. Al-Gathmi)

\section{To cite this article:}

Manal Bilal Mohamed Hassan, Mohamed Ibrahim Osman Ahmed, Sultan Dhaif Allah Awad Alharbi, Uthman Abdull Ah Mohammed Albeshi, Ebtisam Hanshool Mauof Al-Gathmi. Knowledge Attitude and Practice Toward Chikungunya Infection Among Kassala Community in Sudan 2018-2019. American Journal of Nursing Science. Vol. 9, No. 6, 2020, pp. 417-422. doi: 10.11648/j.ajns.20200906.15

Received: November 4, 2020; Accepted: November 17, 2020; Published: November 27, 2020

\begin{abstract}
Introduction: Vector-borne diseases account for over $17 \%$ of all infectious diseases, causing quite 1 million deaths each year global quite 2.5 billion people in over 100 countries are in danger of contracting Dengue. Objective: The study aimed assess Knowledge attitude and practice toward chikungunya virus among Kassala community people of selected area (Kassala in Sudan 2018-2019). Methodology: A community based cross sectional study was conducted in selected area of Kassala city. The study was conducted among 49 participants from 30th December 2018 to January 2019. Simple sampling method was followed for choosing the participants; face-face interview was taken by using structured questionnaire. Result: The results show that respondents had heard of Chikungunya infection $48(97 \%)$, and $43(87 \%)$ responded correctly that Chikungunya is transmitted by Aedes mosquito. Among total 49 only 2 (4\%) had misconceptions that Chikungunya vector breeding in dirty storage water. Study respondents were conscious about clinical features of Chikungunya infection signs and symptoms of Chikungunya p-.000. Study participants use various methods measures against mosquitoes bites including Mosquito repellant cream18 (36\%), Wearing full sleeves shirt 16 (32\%), Electric racquet $16(32 \%)$, and Bed nets $5(10 \%)$ for insect bite prevention. Social network/ media was considered because the most significant and useful source of data on the disease. Conclusion: Community people havegood knowledge about Chikungunya breeding place and methods of prevention of the disease and further adult mosquito control measures play important role for the effective containment of a virulent disease.
\end{abstract}

Keywords: Knowledge, Attitude, Practice, Community People, Chikungunya, Kassala City

\section{Introduction}

Vector-borne diseases account for quite $17 \%$ of all infectious diseases, causing quite 1 million deaths once a year globally. quite 2.5 billion people in over 100 countries are in danger of contracting Dengue. [1] In December 2013, the arboviral disease panorama within the occident changed forever with the primary reported indigenous circulation of the chikungunya virus within the Region of solid ground, on the island of Saint Martin. [2] The word Chikungunya could be a Makonde word (Bantu language) meaning of this word "The one which bends up" pertaining to the posture that the affected patient acquires as a consequence of the pain to the joints [3] Chikungunya virus could be a mosquito-borne virus of the Togaviridae family which is little, spherical, enveloped, positive-strand RNA genome, about 60-70 nm diameter capsid [4] Chikungunya is an alphavirus that's transmitted to humans through mosquito bites. It causes a 
non-specific illness including high fever, severe joint pain, muscle pain, headache, nausea, fatigue, and rash in infected individuals $[5,6]$. While the majority endure the acute illness in 1-2 weeks, there are a proportion of people that still suffer from chronic joint pain which might persist for weeks to years following infection $[5,6]$. Historically, chikungunya virus (CHIKV) has circulated in Africa, Asia, and therefore the Indian and Pacific Islands [6]. In 2013, the virus spread to earth and caused outbreaks in countries that harbor the vectors, yellow-fever mosquito and Aedesalbopictus [6]. Cases of infected travelers in Europe and North America strolling back from CHIKV-affected countries are documented additionally as several small outbreaks in Europe because of importation of the virus into a district with suitable vectors [7]. Chikungunya is a vital public health concern because the virus continues to emerge into previously non endemic areas like terra firma, which have reported over 1.7 million suspected or confirmed cases since 2013 [8]. In the USA, chikungunya has been a notifiable disease since 2015, and within the same year, the Centers for Disease Control and Prevention reported 679 travel-related cases of chikungunya from 44 states [9]. Canada has reported several hundred travel-related cases of chikungunya since it spread to the Americas [10]. Canada disease report CCDR. 2015 [11]. CHIKV characterized by high fever, severe arthralgia, polyarthritis and efflorescence, infections may rarely be related to complications like encephalopathy and hepatic failure [12]. The clinical illness is commonly related to prolonged morbidity, which might impose enormous social and economic disadvantages on affected communities [12]. While the majority pass though the acute illness in 1-2 weeks, there are a proportion of people that still suffer from chronic joint pain which may persist for weeks to years following infection $[12,6]$. Most intervention strategies have focused on mosquito control and insect bite prevention as there's currently no treatment or $r$ vaccine for CHIKV infection in humans [13]. The success of those intervention strategies relies on social factors like knowledge, attitudes, and perceptions of the disease [14]. It's important to grasp how affected populations understand and perceive chikungunya, its transmission cycle, and therefore the importance of control measures to work out what prevention strategies are likely to achieve success. Additionally, how and why the target population chooses to require preventative action against mosquito borne diseases like CHIKV is critical to tell future education and control strategies. Thus, a scientific review was conducted to spot, assess, and analyze the worldwide evidence on the knowledge, attitudes, and perceptions of CHIKV and its transmission in affected populations. In Sudan chikungunya firstly reported in Kassala in 2018/2019 The health authorities in Kassala directed all private practitioners, private and public health facilities to submit daily reports including zero-reporting of cases of Chikungunya Fever; albeit, this action was initiated relatively late during the outbreak. there have been no indicators to point out how initiation of active surveillance was successful in capturing all Chikungunya Fever cases that visited private health facilities. it's been observed that folks opted home and self-treatment because they knew that there was no specific medication to cure for viral diseases which Chikungunya Fever isn't fatal. Some families may need reeled on home treatment thanks to the price of treatment at hospitals [15].

To assess Knowledge attitude and practice toward chikungunya virus among Kassala community people of selected area (Kassala in Sudan 2018-2019).

\section{Methodology}

\subsection{Study Design}

A cross-sectional community based study conducted from 30th September 2018 to January 2019, to assess the knowledge, attitude and practice regard Chikungunya infection, demographic data conducted among community people (age above 18 years) of selected area of Kassala city.

\subsection{Sample Size}

Total sample size was 49 , simple sampling technique used. All participants got questionnaire sheet and explained about the study objective and written consent was obtained. interview was taken by using face to face questionnaire which comprised of (25) questions, and was divided into three sections which included: Section I comprised of Socio demographic details like age, sex, level of education, Source of information about Chikungunya. Section II attitude regard Chikungunya infection and Section III preventive measures practice regard Chikungunya infection.

\subsection{Data Analysis}

Data was analyzed by using statistical software package SPSS-22 version was used for analysis. Using descriptive and inferential statistic for demographic data and inferential statistic regard knowledge, attitude and practice Result was recorded as frequencies, tables and $\mathrm{P}$ values. Level of significance was taken 0.05 .

\section{Results}

Table 1. Socio-demographic data.

\begin{tabular}{lll}
\hline Variable & frequency\% & Total \\
\hline Age by years & \\
$20-25$ & 14 \\
$26-30$ & 21 & 49 \\
\hline
\end{tabular}




\begin{tabular}{lll}
\hline Variable & frequency\% & Total \\
\hline above30 & 14 & 49 \\
Gender & 23 & \\
Male & 26 & 49 \\
Female & 21 & \\
Marital status & 16 & \\
Single & 9 \\
Married & 3 \\
Widow & \\
Divorce & 1 \\
Educational level & 21 \\
Illiterate & 27 \\
Secondaryschool & 0 \\
Graduate & & 49 \\
post graduateothers & 7 \\
Occupation & 13 \\
Student & 23 \\
House wife & 6 \\
Employee & & \\
Others & 3 \\
Source of Information about Chikungunya & 1 \\
Television & 2 \\
Radio & - \\
Newspaper & 30 \\
Family members/Friends & 8 \\
Social network/media (Face book/ etc) & - \\
WhatsApp & 3 \\
Teacher & & 49 \\
Others & & \\
\hline
\end{tabular}

Table 2. Knowledge regard Chikungunya infection.

\begin{tabular}{lllll}
\hline \multirow{2}{*}{ Questions } & Answers & \multirow{2}{*}{ Total Respondents } & P value \\
\cline { 2 - 3 } & Yes & I don't know & \\
\hline Did you heard about Chikungunya? & 48 & 1 & 49 \\
Is Chikungunya fever a disease transmitted by mosquito bite? & 43 & 6 & 49 & .000 \\
Is Chikungunya is caused by virus? & 39 & 10 & 49 & 49 \\
Is Chikungunya is caused by mosquito bite? & 38 & 11 & 49 \\
Is there is any vaccination against Chikungunya? & 20 & 29 & \\
\hline
\end{tabular}

Tabe 3. What is a type of Mosquito transmits Chikungunya.

\begin{tabular}{lllllll}
\hline $\mathbf{Q}$ & Aedes Mosquito & Anopheles Mosquito & Culex Mosquito & I don't know & Total \\
\hline $\begin{array}{l}\text { Respondents } \\
\mathrm{P}-\text { value }\end{array}$ & 6 & 2 & 2 & 39 & 49 \\
\hline
\end{tabular}

Table 4. The symptoms of Chikungunya.

\begin{tabular}{|c|c|c|c|c|c|c|c|c|}
\hline \multirow{2}{*}{ Students answer } & \multicolumn{6}{|c|}{ Answers } & \multirow{2}{*}{ Total } & \multirow{2}{*}{ P value } \\
\hline & Fever & Vomiting & Headache & Joint pain & Rash & Bleeding & & \\
\hline \multirow{6}{*}{ Respondents } & 0 & 0 & 0 & 0 & 0 & 2 & 2 & \multirow{7}{*}{.000} \\
\hline & 6 & 0 & 0 & 0 & 0 & 0 & 6 & \\
\hline & 0 & 7 & 0 & 0 & 0 & 0 & 7 & \\
\hline & 0 & 0 & 9 & 0 & 0 & 0 & 9 & \\
\hline & 0 & 0 & 0 & 0 & 10 & 0 & 10 & \\
\hline & 0 & 0 & 0 & 15 & 0 & 0 & 15 & \\
\hline Total & 6 & 7 & 9 & 15 & 10 & 2 & 49 & \\
\hline
\end{tabular}

Table 5. Time of biting for Chikungunya mosquito.

\begin{tabular}{llllll}
\hline \multirow{2}{*}{ Students answer } & Answers & & & \multirow{2}{*}{ Total } & \multirow{2}{*}{ P value } \\
\cline { 2 - 5 } & During the day & At night & Anytime & 11 & \\
Respondents & 11 & 0 & 0 & 0 & 15 \\
\\
Total & 0 & 15 & 0 & 23 & .000 \\
\hline
\end{tabular}


Table 6. Usual incubation period for Chikungunya.

\begin{tabular}{llllll}
\hline \multirow{2}{*}{ Student answer } & Answers & & & Total & P value \\
\cline { 2 - 5 } & $\mathbf{3 - 4}$ days & $\mathbf{3 - 5}$ days & $\mathbf{3 - 7}$ days & 8 \\
Respondents & 0 & 0 & 0 & 18 & .000 \\
\multirow{2}{*}{ Total } & 0 & 18 & 0 & 23 & \\
\hline
\end{tabular}

Table 7. Chikungunya virus breeding site.

\begin{tabular}{|c|c|c|c|c|c|}
\hline \multirow{2}{*}{ Student code no } & & \multicolumn{2}{|l|}{ Answers } & \multirow{2}{*}{ Total } & \multirow[b]{2}{*}{ P value } \\
\hline & & dirty storage of water & I dont know & & \\
\hline \multirow{3}{*}{$\begin{array}{l}\text { Respondents } \\
\text { Total }\end{array}$} & 2.00 & 0 & 2 & 2 & \\
\hline & 47.00 & 47 & 0 & 47 & .001 \\
\hline & & 47 & 2 & 49 & \\
\hline
\end{tabular}

Table 8. Medical treatment for Chikungunya.

\begin{tabular}{lllllll}
\hline \multirow{2}{*}{ Student code no } & Answers & & & & \multirow{2}{*}{ Total } & P value \\
\cline { 2 - 5 } & Napa / Paracetamol & Pain killers & Antibiotics & I don't know & 49 & .000 \\
\hline Q11 & 10 & 3 & 13 & 23 & 49 & 49 \\
Total & 10 & 3 & 13 & 23 & \\
\hline
\end{tabular}

Table 9. Prevention against bite of mosquito.

\begin{tabular}{|c|c|c|c|c|c|}
\hline \multirow{2}{*}{ Student code no } & \multicolumn{3}{|l|}{ Answers } & \multirow{2}{*}{ Total } & \multirow[b]{2}{*}{ P value } \\
\hline & Wearing full sleeves shirt & Mosquito coil net & I don't know & & \\
\hline Ques & 8 & 36 & 5 & 49 & .000 \\
\hline Total & 8 & 36 & 5 & 49 & \\
\hline
\end{tabular}

Table 10. Attitude regard Chikungunya.

\begin{tabular}{|c|c|c|c|c|}
\hline Variable & Yes & no & total & p-value \\
\hline Chikungunya a deadly disease & 40 & 9 & 49 & .000 \\
\hline Is Chikungunya a preventable disease & 41 & 8 & 49 & .000 \\
\hline Does school \& Ministry of Health provide sufficient knowledge about these Chikungunya & 16 & 33 & 49 & .000 \\
\hline Do you think that Chikungunya should be taught in multimedia & 9 & 40 & 49 & .000 \\
\hline $\begin{array}{l}\text { Do you feel there is a need for conducting workshop/seminar about Chikungunya before the season of its } \\
\text { occurrence }\end{array}$ & 37 & 12 & 49 & .000 \\
\hline Does school curriculum provide sufficient knowledge about Chikungunya & 6 & 43 & 49 & .000 \\
\hline
\end{tabular}

Table 11. Attitude regard Chikungunya-Who/what do you think is the main cause of recent outbreak of Chikungunya).

\begin{tabular}{|c|c|c|c|c|c|c|}
\hline \multirow[b]{2}{*}{ Students answer } & \multicolumn{4}{|l|}{ Answers } & \multirow[b]{2}{*}{ Total } & \multirow[b]{2}{*}{ P value } \\
\hline & $\begin{array}{l}\text { Miss administration of } \\
\text { preventive departments }\end{array}$ & $\begin{array}{l}\text { Neglecting cleanness } \\
\text { and environment }\end{array}$ & $\begin{array}{l}\text { Lack of knowledge and } \\
\text { awareness of people }\end{array}$ & $\begin{array}{l}\text { Heavy } \\
\text { Rainfall }\end{array}$ & & \\
\hline \multirow{4}{*}{ Respondents } & 2 & 0 & 0 & 0 & 2 & \multirow{5}{*}{.000} \\
\hline & 0 & 0 & 0 & 8 & 8 & \\
\hline & 0 & 16 & 0 & 0 & 16 & \\
\hline & 0 & 0 & 23 & 0 & 23 & \\
\hline Total & 2 & 16 & 23 & 8 & 49 & \\
\hline
\end{tabular}

Table 12. Practice about Chikungunya.

\begin{tabular}{lllll}
\hline Variableq1 & Yes & No & total & P value \\
\hline $\begin{array}{l}\text { Does you or your family members regularly check for mosquito breeding sites in and } \\
\text { around your house }\end{array}$ & 46 & 3 & 49 & .000 \\
\hline
\end{tabular}

Table 13. Use of Personal Protective Measures against mosquitoes.

\begin{tabular}{llllllll}
\hline \multirow{2}{*}{ Q2 } & Answers & & & & & Total & P value \\
\cline { 2 - 6 } & $\begin{array}{l}\text { Wearing full } \\
\text { sleeves shirt }\end{array}$ & $\begin{array}{l}\text { Mosquito } \\
\text { repellant cream }\end{array}$ & Bed nets & Insecticide spray & Electric racquet & \\
\hline Respondents & 16 & 18 & 5 & 4 & 6 & 49 & .000 \\
Total & 16 & 18 & 5 & 4 & 6 & 49 \\
\hline
\end{tabular}


Table 14. What is action taken against mosquito breeding.

\begin{tabular}{|c|c|c|c|c|c|c|}
\hline Q3 & $\begin{array}{l}\text { Empty and dry desert } \\
\text { cooler when not in use }\end{array}$ & $\begin{array}{l}\text { Put Kerosene oil in } \\
\text { ponds and swamps }\end{array}$ & $\begin{array}{l}\text { Don't allow water to collect } \\
\text { in tires, broken pots etc }\end{array}$ & $\begin{array}{l}\text { Cover overhead } \\
\text { water tanks }\end{array}$ & Total & $P$ value \\
\hline RespondentsTotal & 12 & 23 & 1 & 13 & 49 & .000 \\
\hline
\end{tabular}

\section{Discussion}

The current study documented the knowledge, attitude and practices regarding chikungunya among kassala population $21(46 \%)$ their average age between 26-30 years and half them in $25-30$ years and above 30 years $36(73 \%)$ of them is female and rest is male, $27(60 \%)$ graduate and employee. Social networking media like Facebook and WhatsApp appeared as emerging sources of knowledge and data in our study $30(61 \%)$, which is in contrast with results obtained by studies by Acharya et al where their respondents reieve their study through newspapers [16]. Most of the study respondents previously heard about Chikungunya infection 48 (98\%) which that that they'd considerable knowledge about Chikungunya infection which they fully recognized breeding sites of Chikungunya vector which is similar to review tired india [17]. In our study respondents knew Time of biting for Chikungunya mosquito in any time of the day, while a rainy seasonal disease, indeed Chikungunya occur within the amount currently summer to early spring session [16]. The results suggest that the bulk of the populations within the captured studies are certain, aware, and understand chikungunya and/or mosquito borne diseases. this could be this reflects that community and private protective actions, are maintained which is in contrast to results of study from systemic review [18]. Their results showed that the bulk of the populations are uncertain, unaware, or don't understand chikungunya and/or mosquito borne diseases. this might be a possible barrier to community and private protective actions. Most of the population were aware that chikungunya 38 $(77 \%)$ were caused by mosquito bites but only $11(22 \%)$ do not know. this may be like results of study by Taran et al [18]. In Malwa region where $80 \%$ students saw this correctly. Regard respondent practice they attentive to program for control mosquito, in Karnataka reported $60 \%$, Patel et al. were conscious of government programme for control of mosquito borne diseases, which came on line with our study where $p$-value.000 [19]. The preventive practices noted in our study were more towards Wearing full sleeves shirt and Mosquito repellant cream to shield themselves this implies the participants has good practice regard prevention of chikungunya infection $p .000$, this is in contrast with study results were noted in an exceedingly study exhausted Yemen on urban communities [20].

\section{Conclusion and Recommendation}

The study reflects good knowledge attitude and practice regard Chikungunya but the disease should be more preventable and it'd require a planned approach, besides knowledge and awareness of early warning signs for community, for prevention. And since of small sample we'd wish to panned educated program for Integrated vector management through the elimination of breeding sites, use of anti-adult and anti-larval measures and private protection will contribute to preventing a virulent disease. Community empowerment and mobilization is crucial for prevention and control of chikungunya. Adult mosquito control measures like fogging often applied by the civic authorities united tool might not by itself contribute to the effective containment of a virulent disease.

\section{References}

[1] Fact Sheet on Vector Borne Diseases, World Health Organizationhttp://www.who.int/mediacentre/factsheets/fs387/ en/.

[2] Pan American Health Organization (2013). Epidemiological alert. Chikungunya fever. 9 December 2013. Washington, D.C.: PAHO; Available at: http://www.paho.org/hq/index.php?option=com_docman\&task $=$ doc_view\&gid $=23806+\&$ Itemid $=270 \&$ lang $=$ en Accessed on 23 May 2017.

[3] Robinson MC. An epidemic of virus disease in Southern Province, Tanganyika territory. 1955, in 1952-1953. Trans R Soc Trop Med Hyg. 1: 28-32. 1955.

[4] World Health Organization. Guidelines for prevention and control of chikungunya fever. (2009). World Health Organization, Regional Office for South-East Asia, New Delhi.

[5] Staples EJ, Breiman RF, Powers AM. (2009). Chikungunya fever: an epidemiological review of a re-emerging infectious disease. Clin Infect Dis. doi: 10. 1086/605496.

[6] Thiberville SD, Moyen N, Dupuis-Maguiraga L, Nougairede A, Gould EA, Rogues P, et al. (2013). Chikungunya fever: epidemiology, clinical syndrome, pathogenesis and therapy. Antivir Res. 2013. doi: 10.1016/j.antiviral..06.009.

[7] Centers for Disease Control and Prevention. Chikungunya virus. 2015. https://www.cdc.gov/chikungunya/geo/unitedstates-2015.html. Accessed 22 July. (2016). European Centre for Disease Control and Prevention. Chikungunya. 2016. https://ecdc.europa.eu/en/chikungunya. Accessed.

[8] Pan American Health Organization. Chikungunya. 2 (016). http://www.paho.org/hq/index.php?option=com_topics\&view $=$ article \&id=343\&Itemid $=40931$.

[9] Drebot MA, Holloway K, Zheng H, Ogden NH.(2014). Travel-related chikungunya cases in Canada.

[10] http://www.phac-aspc.gc.ca/publicat/ccdr-rmtc/15vol41/drrm41-01/rapideng.php (2016).

[11] Enserink, M. (2007). Chikungunya: no longer a third world disease. Science 318, 1860-1861. 
[12] World Health Organization. Neglected tropical diseases. (2016). http://www.who.int/neglected_diseases/vector_ecology/VCA $\mathrm{G} / \mathrm{en} /$.

[13] Hassan E El Bushra, Betigel W Habtewold, Naeema Al Gasseer, Rehab E Mohamed, Salim A Mohamednour, et al. (2019). Outbreak of Chikungunya Fever in Sudan,. JOJ Pub Health.; $4 \quad$ (3): $555644 . \quad$ DOI: 10.19080/JOJPH.2019.04.555644003).

[14] Acharya A, Goswami K, Srinath S, Goswami A. (2005). Awareness about Dengue syndrome and related preventive practices amongst residents of an urban resettlement colony of south Delhi. J Vect Borne Dis., 42: 122-7.

[15] Vijayakumar KP, Anish TS, George B, Lawrence T, Muthukkutty SC, et al. (2011). Clinical profile of chikungunya patients during the epidemic of 2007 in Kerala, India. J Glob Infect Dis 3: 221 .
[16] Rashid Md HO, Sultana H, Zzaman MdT. Knowledge (2018). Awareness Regarding Chikungunya among Urban Community People of Selected Area of Dhaka City Bangladesh. J Infect Dis Ther 6: 355. doi: 10.4172/2332-0877.1000355.

[17] Tricia Corrin, et al. (2017). Tropical Medicine and Health45: 21DOI 10.1186\s;2017.41182-017-0061-x.

[18] Taran SJ, Taran R, Bhandari V. (2016). Knowledge, awareness and practice study for mosquito bornediseases among school children of Malwa region of India. Indian J Child Health.; 3 (2): $125-128$

[19] Patel AB, Rathod H, Shah P, Patel V, Garsondiya J, Sharma (2011). Perceptions regarding mosquito borne diseases in an urban of Rajkot city. Natl J Med Res.; 1 (2): 45-7.

[20] Alyousefi T, Abdul-Ghani R, Mahdy M, et al. (2016). A household-based survey of knowledge, attitudes and practices towards dengue fever among local urban communities in Taiz Governorate, Yemen. BMC Infect Dis; 16. 